\title{
Study on radiation power density effects on flight performance
}

\author{
X. JIN \& Y. J. HONG \& D.P. WANG \\ State Key Laboratory of Laser Propulsion \& Application, Equipment Academy, Beijing, China
}

KEYWORD: Laser, UAV, Radiation, Power density, Maximum level flying speed

ABSTRACT: Laser-motive UAV (unmanned aerial vehicles) is a new concept UAV. Based on analysis of conservation equation of photoelectric conversion irradiated by laser energy, UAV load's demand for power density and heat convection balance, a model is established to analyze the relationship between UAV maximum level flying speed, maximum wing loading and laser irradiation power density, propulsion system output power, photovoltaic cells operating temperature, and further a method is proposed to calculate and analyze UAV flying height, maximum level flying speed and maximum wing loading, etc. The calculation and analysis method proposed in this thesis provides basis for the design and analysis of Laser-motive UAV.

\section{INTRODUCTION}

The working principle of Laser-motive UAV is that, laser irradiates photovoltaic cells, then photovoltaic cells convert laser energy into electrical energy, and the power tracker ensures maximum power output of photovoltaic cells, the converted electrical energy supplying the load, including propulsion system( motor controllers, motors, gearboxes, propellers, etc.), payload and electronic equipment (including buck converter $)^{[1]}$. The battery supplies the load at relatively short time if clouds block emerges.

Based on impact analysis of radiation power density on UAV flight performance, the following issues are addressed: how much power density of laser radiation should be; after deduction of payload and electronic equipment power, how much power can propulsion systems get; how much power can be output from UAV propulsion system; in certain output power from propulsion system, how is the UAV flight performance.

\section{OUTPUT POWER OF LASER-MOTIVE UAV}

The power that loads (propulsion system, payload and electronic equipment, etc.) get from laser energy transmission is $P_{\text {offer }}$. According to the energy conservation conditions, the below is get ${ }^{[2]}$ :

$$
I_{s} A_{\text {solar }} T_{\text {day }} k_{\text {light }} \eta_{\text {panel }} \eta_{\text {mppt }}=P_{\text {offer }}\left(T_{\text {day }}+\frac{T_{\text {night }}}{\eta_{\text {chrg }} \eta_{\text {dischrg }}}\right)
$$

where, $I_{s}$ is the laser irradiation power density; $A_{\text {solar }}$ is photovoltaic cell area; $T_{d a y}$ is laser irradiation time; $T_{n i g h t}$ is battery operating time and meets $T_{\text {day }}+T_{\text {night }}=24 \mathrm{~h} ; k_{\text {light }}$ is atmospheric impact factor (clouds and atmospheric pollution); $\eta_{\text {panel }}$ is energy conversion efficiency of photovoltaic cells; $\eta_{m p p t}$ is power tracker efficiency; $\eta_{\text {chrg }}$ and $\eta_{\text {dischrg }}$ is separately battery charging efficiency and discharging efficiency.

Define the wing area of UAV as $S=b^{2} /(A R)$ ( $b$ : wingspan, $A R=b / c$ : aspect Ratio, $c$ : the chord ), photovoltaic cells laid ratio (photovoltaic cell area and the wing area ratio) as $R=A_{\text {solar }} / S<1$, then photovoltaic cell area is $A_{\text {solar }}=R S$.

Therefore, the overall power that laser output meets Equation (1).

$$
P_{\text {offer }} / S=\frac{I_{s} R k_{\text {light }} \eta_{\text {panel }} \eta_{\text {mppt }}}{1+\frac{T_{\text {night }} / T_{\text {day }}}{\eta_{\text {chrg }} \eta_{\text {dischrg }}}}
$$

Electronic equipment power and payload power $P_{c t r l}+P_{\text {payload }}$ are given, and the buck converter efficiency is $\eta_{B E C}$, then the power provided for electronic equipment and payload is: 


$$
P_{\text {ctrl, payload }}=\frac{1}{\eta_{B E C}}\left(P_{\text {ctrl }}+P_{\text {payload }}\right)
$$

Define $K=P_{\text {ctrl,payload }} / P_{\text {offer }}$ (total power percentage of electronic equipment and payload power), then the power propulsion systems get from the total power laser energy transmission provided is given in Equation (2).

$$
P_{\text {prop }}=P_{\text {offer }}-\frac{1}{\eta_{B E C}}\left(P_{\text {crrl }}+P_{\text {payload }}\right)=(1-K) P_{\text {offer }}
$$

In this case, the power propulsion system outputs can be expressed as below, where, $\eta_{\text {ctrl }}$ is the efficiency of the motor controller; $\eta_{\text {mot }}$ is the efficiency of the gearbox; $\eta_{\text {prop }}$ is the efficiency of the propeller.

$P_{\text {out }}=\eta_{\text {crtrl }} \eta_{\text {mor }} \eta_{\text {grbox }} \eta_{\text {prop }} P_{\text {prop }}$

Thus, the power that Laser-motive UAV outputs is given in Equation (3).

$$
P_{\text {out }} / S=\eta_{\text {crrlr }} \eta_{\text {mot }} \eta_{\text {grbox }} \eta_{\text {prop }}(1-K) \frac{I_{s} R k_{\text {light }} \eta_{\text {panel }} \eta_{\text {mppt }}}{1+\frac{T_{\text {night }} / T_{\text {day }}}{\eta_{\text {chrg }} \eta_{\text {dischrg }}}}
$$

Namely, the functional relationship between laser irradiation power density and aircraft parameters is established, and the main factors of UAV output power are as follows.

(1) Laser irradiation power density $I_{s}$ and air quality impact $k_{\text {light }}$.

(2) The percentage $K$ that electronic equipment and payload power shares in overall power.

(3) Battery usage patterns $T_{n i g h t} / T_{d a y}$.

(4) Other subsystem parameters of UAV.

\section{The maximum level flying speed and maximum wing loading}

On horizontal flight conditions, if the thrust $T$ equals to the resistance $D$, the below is get, where $C_{D}$ is the drag coefficient; $S$ is the wing area, $\rho$ is atmosphere density; $V$ is the aircraft speed.

$T=D=C_{D} \frac{1}{2} \rho V^{2} S$

The greater flying speed is, the greater the resistance is, and the required power to overcome resistance $P_{\text {out }}=D V$, then the maximum level flying speed is shown as Equation (4).

$$
V_{\text {max }}=\left(\frac{2 P_{\text {out }}}{C_{D} \rho S}\right)^{1 / 3}
$$

Obviously, the maximum level flying speed is related to propulsion system's output power $P_{\text {out }}$ and flying altitude (atmospheric density is a function of flying height).

When in subsonic flight, the drag coefficient can be expressed as below.

$C_{D}=C_{D 0}+C_{D i}, C_{D i}=\frac{C_{L}^{2}}{\pi(A R) e}$

In the above formula, $C_{D 0}$ is zero lift drag coefficients (zero lift drag coefficient does not change with lift variation); $C_{D i}$ is induced drag coefficient (with lift variation), $C_{D i}$ is Oswald efficiency factor.

On horizontal flight conditions, lift equals weight and the minimum speed is get as below.

$$
L=\frac{1}{2} C_{L} \rho V_{\min }^{2} S=W, V_{\min }=\left(\frac{2 W}{C_{L} \rho S}\right)^{1 / 2}
$$

Let $V_{\max } \geq V_{\min }$, the maximum wing loading is:

$$
W / S \leq \frac{C_{L} \rho V_{\max }^{2}}{2},(W / S)_{\max }=\frac{C_{L} \rho V_{\max }^{2}}{2}
$$




\section{Heat flux of convection cooling}

Laser-motive UAV generally use passive cooling, and the photovoltaic cells convection-cooled heat flux (unit: $\mathrm{Wm}^{-2}$ ) is as below.

$q_{w}=2 \rho V c_{p}\left(T_{a w}-T_{\text {panel }}\right) C_{H}$

In the above formula, $T_{a w}<T_{\text {panel }}$ represents photovoltaic panels to heat; $\rho$ is atmospheric density; $V$ is flying speed; $c_{p}$ is atmospheric specific heat capacity; $T_{\text {panel }}$ is the photovoltaic cell temperature; $C_{H}$ is the Stanton number; $C_{H}$ can be expressed as below ${ }^{[3]}$.

$C_{H}= \begin{cases}\frac{0.332}{\sqrt{\operatorname{Re}_{x}^{*}}\left(\operatorname{Pr}^{*}\right)^{-2 / 3}} & \text { Laminar flow } \\ \frac{0.185}{\left(\log _{10} \operatorname{Re}_{x}^{*}\right)^{2.584}}\left(\operatorname{Pr}^{*}\right)^{-2 / 3} & \text { Turbulent flow }\end{cases}$

where, Reynolds $\operatorname{Re}_{x}^{*}$ and Reynolds $\operatorname{Pr}^{*}$ is shown below:

$\operatorname{Re}_{x}^{*}=\frac{\rho^{*} V x}{\eta^{*}}, \operatorname{Pr}^{*}=\frac{c_{p}^{*} \eta^{*}}{\lambda^{*}}$

In the above formula, $x$ is the characteristic size of photovoltaic cells(namely UAV chord). The flow boundary layer is laminar flow when $x \leq x_{c}$, otherwise turbulence. The critical Reynolds number adopts $\operatorname{Re}_{c}^{*}=\rho^{*} V x_{c} / \eta^{*}=5 \times 10^{5}$, the reference temperature of Reynolds $\operatorname{Re}_{x}^{*}$ and Prandtl number $\operatorname{Pr}^{*}$ can be calculated as Equation(7), where, $T_{\infty}$ is undisturbed gas temperature in UAV flying altitude; $M_{\infty}$ is the Mach number. Atmospheric parameters (atmospheric density, dynamic viscosity, specific heat capacity and thermal conductivity) are calculated using USSA76 atmospheric model ${ }^{[4]}$.

$T^{*}=T_{\infty}\left[1+0.032 M_{\infty}^{2}+0.58\left(T_{w} / T_{\infty}-1\right)\right]$

Adiabatic wall temperature is given as below.

$T_{a w}= \begin{cases}T_{\infty}\left[1+(\operatorname{Pr})^{1 / 2} \frac{\gamma-1}{2} M_{\infty}^{2}\right] & \text { Laminar flow } \\ T_{\infty}\left[1+(\operatorname{Pr})^{1 / 3} \frac{\gamma-1}{2} M_{\infty}^{2}\right] & \text { Turbulent flow }\end{cases}$

In the above formula, the adiabatic wall temperature $T_{a w}$ is the boundary temperature when layer flow without heat exchange with photovoltaic cell temperature. When it comes to atmosphere, $\gamma=1.4$ is selected. The Prandtl number $\operatorname{Pr}=c_{p} \eta / \lambda$ is a dimensionless quantity $\left(c_{p}\right.$ is the air specific heat capacity, units: $\mathrm{J}(\mathrm{kg} \cdot \mathrm{K})^{-1} \cdot \eta$ is dynamic viscosity, unit: $\mathrm{Pa} \cdot \mathrm{s}, \mathrm{N} \cdot \mathrm{s} \cdot \mathrm{m}^{-2}$ or $\mathrm{kg}(\mathrm{ms})^{-1} \cdot \lambda$ is thermal conductivity, units: $\left.\mathrm{W}(\mathrm{mK})^{-1}\right)$.

\section{Heat balance equation to Photovoltaic cells}

Energy conversion efficiency of photovoltaic cells is $\eta_{\text {panel }}$. Heat flux density is $I_{s} k_{\text {light }}\left(1-\eta_{\text {panel }}\right)$ in irradiation of laser power density $I_{s}$. Taking the exchange between atmosphere and the Earth's radiant heat, the heat balance equation is expressed as below.

$$
I_{s} k_{\text {light }}\left(1-\eta_{\text {panel }}\right)+q_{w}-2 \varepsilon \sigma_{S B} T_{\text {panel }}^{4}+\varepsilon \sigma_{S B} T_{s k y}^{4}+\varepsilon \sigma_{S B} T_{\text {earth }}^{4}=0
$$

where, $\sigma_{S B}=5.67 \times 10^{-8} \mathrm{Wm}^{-2} \mathrm{~K}^{-4}$ is Stefan-Boltzmann constant. The radiation emission rate is $\varepsilon=0.9$, and earth temperature is $T_{\text {earth }}=288^{\circ} \mathrm{K}\left(15^{\circ} \mathrm{C}\right)$.

Atmosphere effective temperature $T_{s k y}$ is a function of flying altitude, and becomes lower if height becomes higher. According to Modtran calculations, the effective temperature can be approximately taken as below. 
$T_{s k y}=\left\{\begin{array}{l}\frac{270-130}{-13000}(h-13000)+130 \quad(0 \leq h \leq 13000 \mathrm{~m}) \\ \frac{130-30}{13000-70000}(h-70000)+30 \quad(13000 \mathrm{~m} \leq h \leq 70000 \mathrm{~m})\end{array}\right.$

The energy conversion efficiency of photovoltaic cells $\eta_{\text {panel }}$ is related to operating temperature $T_{\text {panel }}$, as shown in Equation (11) below.

$\frac{\mathrm{d} \eta_{\text {panel }}}{\eta_{\text {panel }}-\eta_{\text {nominal }}}=\frac{\mathrm{d} T_{\text {panel }}}{T_{\text {panel }}-T_{\text {nominal }}}$

where the standard operating temperature $T_{\text {nominal }}=298 \mathrm{~K}\left(25^{\circ} \mathrm{C}\right)$. The higher the temperature is, the lower is the energy conversion efficiency, and $\mathrm{d} \eta_{\text {panel }} / \mathrm{d} T_{\text {panel }}$ is negative.

The standardization temperature coefficient of photovoltaic cells $\left(1 / \eta_{\text {panel }}\right) \mathrm{d} \eta_{\text {panel }} / \mathrm{d} T_{\text {panel }}$ is proportional to the band gap energy of photovoltaic materials, which can be approximated as a constant $C<0$. Therefore, the relationship between energy conversion efficiency of photovoltaic cells and the operating temperature is approximately expressed as Equation $(12)^{[5]}$.

$\eta_{\text {panel }}=\frac{\eta_{\text {nominal }}}{1-C\left(T_{\text {panel }}-T_{\text {nominal }}\right)} \quad C<0$

\section{Calculation and analysis}

Take Sky Sailor solar UAV prototype as a reference, chosen parameters are as follows: lift coefficient $C_{L}=0.8$, zero lift drag coefficient $C_{D 0}=0.013$, aspect ratio $A R=12$, chord $c=0.3 \mathrm{~m}$ (wingspan $b=3.6 \mathrm{~m}$ ), Oswald efficiency factor $e=0.9$; power tracking efficiency $\eta_{\text {mppt }}=0.97$, the charging efficiency of batteries $\eta_{\text {chrg }}=0.98$, the discharge efficiency $\eta_{\text {dischrg }}=0.98$; the motor controller, gear box, motor and propeller efficiency is respectively $\eta_{c r l r}=0.95, \eta_{\text {grbox }}=0.95, \eta_{\text {mot }}=0.85$ and $\eta_{\text {prop }}=0.85$.

According to current good quality photovoltaic cells, we choose standard temperature of photovoltaic cells $T_{\text {nominal }}=298.0 \mathrm{~K}$, energy conversion efficiency of photovoltaic cells under standard temperature $\eta_{\text {nominal }}=0.4$, standardization temperature coefficient $C=-0.0025$, laying ratio of photovoltaic cells $R=0.5$, the percentage of electronics power and payload taken in total power $K=1 / 250$, laser irradiation time $T_{n i g h t}=2 \mathrm{~h}$ ( usually the clouds block time is no more than $2 \mathrm{~h}$ ), Earth radiation temperature $T_{\text {earth }}=288.0 \mathrm{~K}$, Stefan-Boltzmann constant $\sigma_{S B}=5.67 \times 10^{-8} \mathrm{Wm}^{-2} \mathrm{~K}^{-4}$, the emissivity $\sigma=0.9$, atmospheric factor $k_{\text {light }}=0.7$.

Figure 1 shows the maximum level flying speed varies with flying height and laser irradiation power density, which indicates the bigger laser irradiation power density is, the higher is flying height, and the greater is the maximum level flying speed.

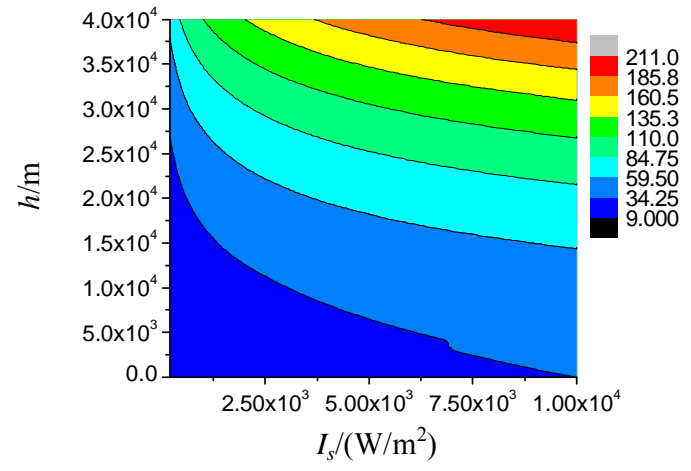

Figure 1. The maximum level flying speed varies with flying height and laser irradiation power density. 


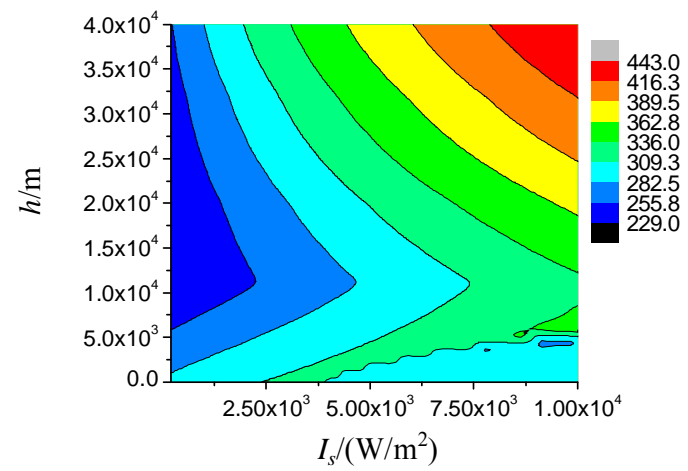

Figure 2. Operating temperature of the photovoltaic cell varies with laser irradiation power density and flying height

Figure 2 shows the operating temperature of the photovoltaic cell varies with laser irradiation power density and flying height. In $5 \mathrm{~km} \sim 25 \mathrm{~km}$ altitude, the temperature of photovoltaic battery is relatively low, so the laser irradiation power density can be larger. When the laser irradiation power density is $10000 \mathrm{~W} / \mathrm{m}^{2}$ and flying height is more than $30 \mathrm{~km}$, photovoltaic cells cannot work properly due to high operating temperatures.

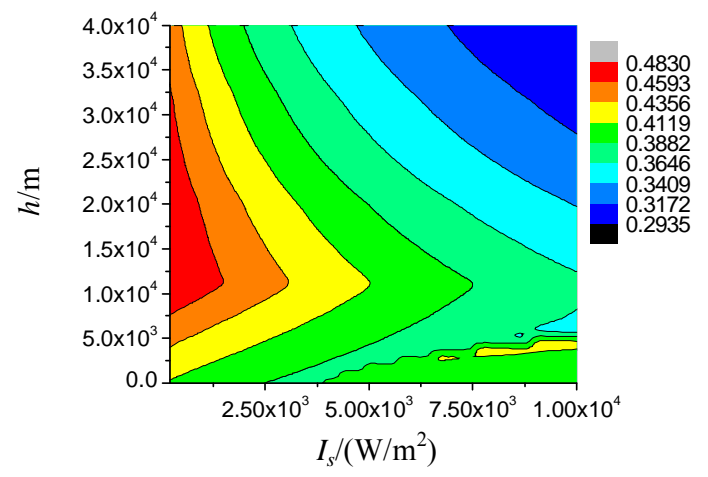

Figure 3. Energy conversion efficiency of photovoltaic cells varies with laser power density and flight level change.

Figure 3 shows the energy conversion efficiency of photovoltaic cells varies with laser power density and flight level change. In the $5 \mathrm{~km}-25 \mathrm{~km}$ flying altitude, there is a high energy conversion efficiency of photovoltaic cells (due to low temperature), so larger laser radiation power density can be used. When power density of laser irradiation is $10000 \mathrm{~W} / \mathrm{m} 2$ and the flying altitude is more than $30 \mathrm{~km}$, the energy conversion efficiency decreases since photovoltaic battery temperature is too high.

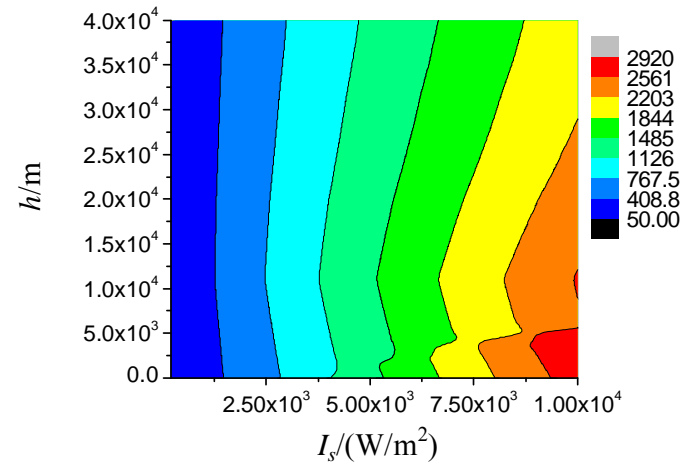

Figure 4. Power density available for load varies with laser irradiation power density and flying height.

Figure 4 shows the power density available for load varies with laser irradiation power density and flying height, and the greater is the power density of laser irradiation, the greater is the power density available for load. Below flying altitude $5 \mathrm{~km}$, when the laser power density is $10000 \mathrm{~W} / \mathrm{m}^{2}$, the injection photovoltaic cell power density is $I_{s} k_{\text {light }}=10000 \times 0.7=7000 \mathrm{~W} / \mathrm{m}^{2}$, the power density available for load is $I_{s} k_{\text {light }} \eta_{\text {panel }}>2500 \mathrm{~W} / \mathrm{m}^{2}$.

Figure 5 shows the UAV propulsion system output power varies with laser irradiation power density and flying height, and the greater is the power density of laser irradiation, the greater is the propulsion system output power. In the $5 \mathrm{~km}-25 \mathrm{~km}$ flying altitude, there is a high energy conversion effi- 
ciency of photovoltaic cells due to high propulsion system output power. Below flying altitude $15 \mathrm{~km}$, when the laser power density is $10000 \mathrm{~W} / \mathrm{m}^{2}$, the injection photovoltaic cell power density is $I_{s} k_{\text {light }}=10000 \times 0.7=7000 \mathrm{~W} / \mathrm{m}^{2}$. Although the area of photovoltaic cells is as small as $A_{\text {solar }}=0.3^{2} \times 12 \times 0.5=0.54 \mathrm{~m}^{2}$, the propulsion system output power is as big as $630 \mathrm{~W}$ or more.

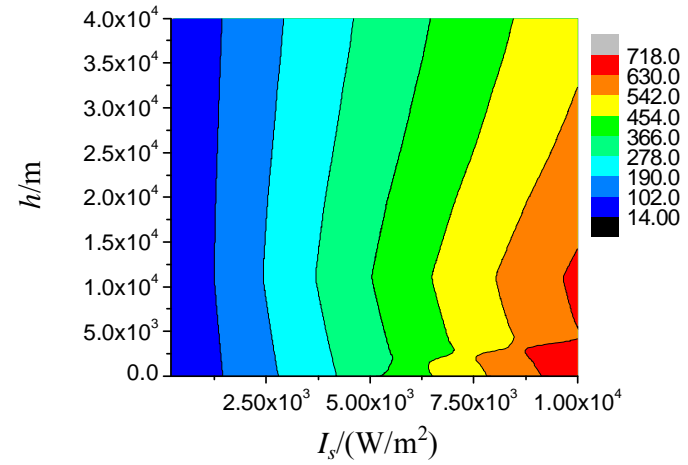

Figure 5. The UAV propulsion system output power varies with laser irradiation power density and flying height.

Figure 6 shows the UAV wing loading varies with laser irradiation power density and flying height, and the greater is the power density of laser irradiation and the smaller is flying height, the greater is the wing loading.

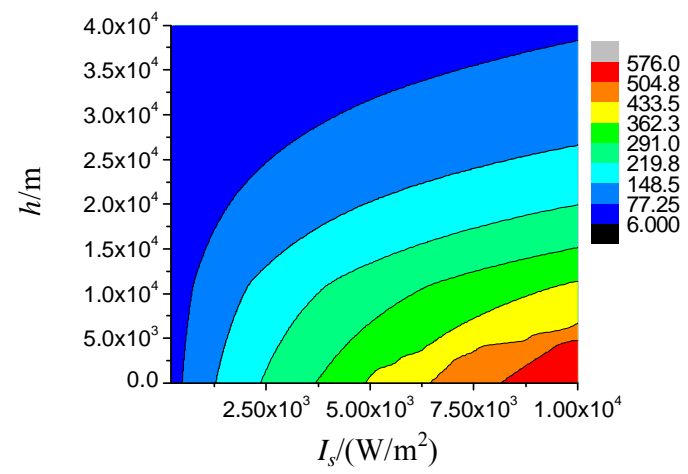

Figure 6. UAV wing loading varies with laser irradiation power density and flying height.

\section{REFERENCES}

[1]Bohn W L. Laser lightcraft performance [C].Proc of SPIE. 2000, 3885: 48-53.

[2]Edward H. Allen. The case for near space [J]. Aerospace America, 2006, (2):31-34.

[3]Myrabo L N,Raizer Y P and Surzhikov. Air plasma formation in MHD slipstream accelerator for mercury lightcraft [A]. Second International Symposium on Beamed Energy Propulsion [C], 2004, 534-543.

[4]Ageichik A A,Egorov M S,Rezunkov Y A,et al. Experimental study on thrust characteristics of airspace laser propulsion engine [A]. Second International Symposium on Beamed Energy Propulsion [C], 2004, 49-60.

[5]Jin X et al. Concept research of laser-motive UAV [J]. Acta Aeronautica et Astronautica Sinica, 2013, 34(9):2074-2080. 